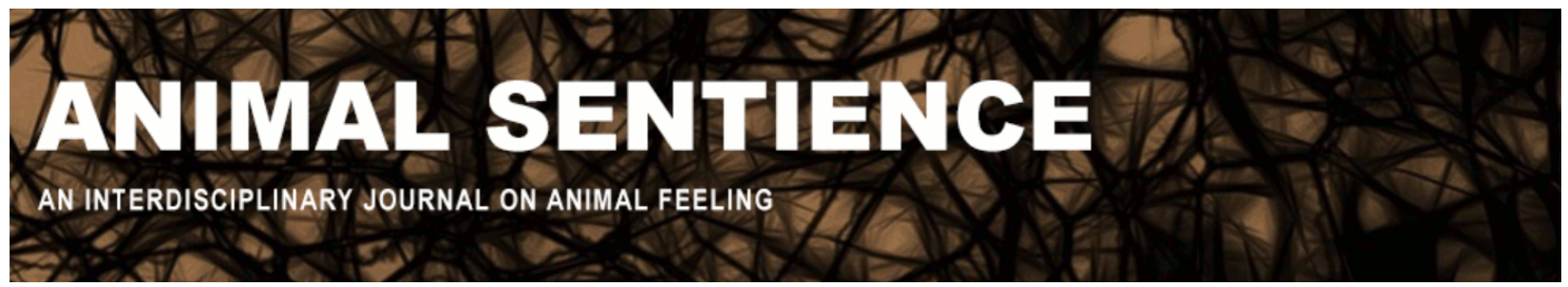

Cartmill, Matt (2020) Do beetles have experiences? How can we tell?. Animal Sentience 29(31)

DOI: $10.51291 / 2377-7478.1618$

Date of submission: $2020-07-11$

Date of acceptance: 2020-07-18

(c)

This article has appeared in the journal Animal

Sentience, a peer-reviewed journal on animal

cognition and feeling. It has been made open access,

free for all, by WellBeing International and deposited

in the WBI Studies Repository. For more information,

please contact

wbisr-info@wellbeingintl.org.

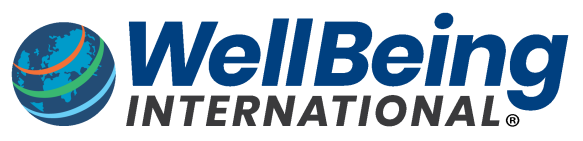

SOLUTIONS FOR PEOPLE, ANIMALS AND ENVIRONMENT 


\title{
Do beetles have experiences? How can we tell?
}

\author{
Commentary on Mikhalevich \& Powell on Invertebrate Minds
}

\author{
Matt Cartmill \\ Department of Anthropology, Boston University
}

\begin{abstract}
We attribute consciousness to other humans because their anatomy and behavior resembles our own and their verbal descriptions of subjective experiences correspond to ours. Nonhuman mammals have somewhat humanlike behavior and anatomy, but without the verbal descriptions. Their sentience is therefore open to Cartesian doubt. Robot "minds" lack humanlike behavior and anatomy, and so their sentience is generally discounted no matter what sentences they generate. Invertebrates lack both neurological similarity and language. Although it may be safest in making moral judgments to assume that some invertebrates are sentient, cogent reasons for thinking so must await an objective causal explanation for subjective experience.
\end{abstract}

Matt Cartmill is a biological anthropologist. He has written extensively on human and mammalian evolution, comparative anatomy, theory of systematics, quadrupedal locomotion, animal consciousness, the moral standing of animals, and the history and philosophy of science. Website

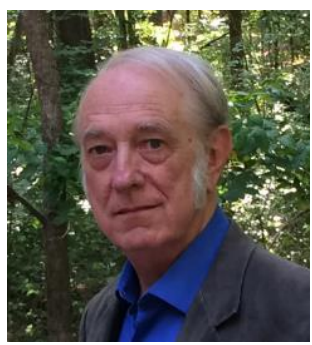

I agree with Mikhalevich \& Powell (2020) that "Phenomenal consciousness is... a precondition for moral standing" in the fullest sense of that term, and that "some form of mental life is a precondition for morally protectable interests." It is therefore morally important to know whether cats, fish, or beetles are sentient. How can we tell?

I know that I am conscious most of the time. I believe that other people are also conscious most of the time, because they are very like me in:

(A) their anatomy and physiology,

(B) their general behavior (e.g., their responses to stimuli), and

(C) their verbal testimony about their subjective experiences

These three kinds of evidence justify that intuitive belief in the consciousness of other people. They also warrant the belief that, like me, other people experience periods of unconsciousness, mainly during sleep. Waking and sleeping are distinguished by different patterns of neural activity in the brain, suggesting that consciousness is the product of particular patterns of brain activity, rather than brain anatomy per se.

Some sleepers open their eyes, walk around, and perform various waking-type activities while manifesting slow brain waves and other correlates of sleeping unconsciousness. On being aroused from this "sleepwalking" state, they often display surprise and disorientation. They may report having no recollection of their sleepwalking activities. Though the behavior of sleepwalkers is usually somewhat abnormal or defective (especially in linguistic performance), 
they may do some distinctively human things, including driving cars and playing musical instruments (Zadra \& Pilon 2012, Perreault 2014). These facts indicate that even fully human brain anatomy and distinctively human behavior do not guarantee phenomenal consciousness.

How do we know that other animals are sentient? Are they sleepwalking even when they appear to be awake? Here we are on uncertain ground. Many nonhuman animals alternate between discrete states of wakefulness and sleep, and it is natural to think that this disjunction corresponds to a subjective difference between consciousness and unconsciousness, as it does in humans. But the analogy is imperfect with respect to traits (A) and (B) above, and wholly deficient with regard to (C). The brains and behavior of (say) dogs are somewhat like ours in many ways, but hardly identical. Most important, dogs cannot give us any verbal reports on their experiences. In principle, some degree of Cartesian skepticism about their sentience is therefore warranted. In practice, we nevertheless all assume that dogs feel pain when we tread on them and they yelp. This seems like the safest assumption from a moral standpoint.

In the case of machines, we encounter deficiencies in both traits (A) and (B). Properly programmed, computers can generate appropriate-sounding written sentences laying claim to all sorts of subjective experiences, although their verbal behavior (like that of sleepwalkers) usually falls short of being convincingly human. The causal underpinnings of that verbiage (trait A), however, and the behavioral context in which it emerges (trait B), are so utterly unlike those of humans that few attribute sentience to such machines or regard them as deserving moral consideration.

Invertebrates also have two kinds of deficiencies: their "brains" and other organs are not homologous with those of humans (trait A), and they cannot generate verbal reports on their internal states (trait C). The case for their sentience can rest only on analogies between their alien neurology and aspects of human neurology known to be correlated with states of conscious awareness (trait A), or between their behavior and analogous human behaviors known to be reliable signals of mental states (trait B).

M\&P draw analogies of both sorts. In seeking neurological analogies, they point to "structural characteristics that could support sophisticated forms of cognition" in arthropods and molluscs, including "central processing regions... that continuously receive, integrate, and exchange information with peripheral systems... permitting centralized coordination of multimodal sensory information and executive (top-down) control." But the computer metaphors implicit in this analogy betray its fatal flaw: any structural arrangement claimed to cause and demonstrate phenomenal consciousness can be modeled in machine systems that are (almost) surely not sentient (Van Hateren 2016). The unfortunate fact is that we have no theory of the causes of consciousness that can justify inferring sentience from some neurological arrangement.

M\&P point to neurochemical and behavioral changes in insects and cephalopods following various sorts of stimuli as evidence for emotionally glossed conscious experience: distress in injured shrimps, aspirational intentionality in hermit crabs, pessimism in shaken bumblebees, and so on. But trying to infer emotional mental glosses from animal behavior runs into what I once called the Darwinist's Dilemma:

We can reliably infer subjective pain from the yelp of a kicked dog only if the yelp serves no objective purpose. If it can be seen as adaptively useful-say, by serving to alert nearby kin to danger-then we can argue with 
Malebranche that God or natural selection has simply endowed dogs with a mechanical squeaker to enhance their reproductive fitness, and that "if they act in what seems to be an intelligent and purposive manner, it is only because God has made them fit to survive." (Cartmill 2000, p. 840).

Likewise, a bumblebee may be more averse to risk after a vigorous shaking, not because the shaking has filled it with pessimistic feelings, but because increased caution is on the whole an adaptive response to a more dangerous environment, and will be programmed by natural selection into the mechanical responses of a well-adapted bumblebee.

M\&P make two important points that should inform future debate on this issue. First, it is imperative that we stop equating phylogenetic proximity to Homo sapiens with the vertical dimension on the scala naturae, after the fashion of Morgan's Canon. The scala naturae is a myth. Second, we have no reason to assume that a very small lump of neurons cannot produce phenomenal consciousness, because we have no idea how or why objective, observable phenomena can produce sentience. It may not take anything like a human brain to do it. But until we know how to do it and why it happens, conjectures about sentience in invertebrates, and decisions about their moral status, will depend on our individual intuitions as to what constitutes a safe bet.

\section{References:}

Cartmill, M. (2000) Animal consciousness: Some philosophical, methodological, and evolutionary problems. American Zoologist 40: 835-846.

Mikhalevich, Irina \& Powell, Russell (2020) Minds without spines: Evolutionarily inclusive animal ethics. Animal Sentience 29(1)

Perreault, R. (2014) Analyse de l'activité en ondes lentes et des oscillations lentes chez les somnambules. Doctoral thesis, University of Montréal.

Van Hateren, J. H. (2016) Insects have agency but probably not sentience because they lack social bonding. Animal Sentience 2016.108.

Zadra, A., \& Pilon, M. (2012). Parasomnias II: Sleep terrors and somnambulism. In C. Morin \& C. Espie (eds.), The Oxford handbook of sleep and sleep disorders, pp. 574-593. Oxford: Oxford University Press. 